\title{
AN EXPLORATORY STUDY OF THE CRITICAL NEED FOR SCHOOL HEALTH PROGRAMS IN LEBANON
}

\author{
JABBOUR, Khayrazad Kari ${ }^{1^{*}}$ \\ Lebanese University, Faculty of Pedagogy, Beirut Lebanon \\ Phone: +961-1-292 981; Mob: +961-70-238 095 \\ e-mail: karijabbour@hotmail.com
}

Received 01 July 2013; received in revised form 30 November 2013; accepted 14 January 2014

\section{RESUMO}

As escolas desempenham um papel vital no estabelecimento de padrões de comportamentos saudáveis entre os jovens que, por sua vez, carregam esses padrões na vida adulta. Este artigo explora e recolhe informações sobre os programas de saúde escolar e práticas de saúde nas escolas Libanesas. A meta desta pesquisa é fornecer informações básicas para os formadores de política escolar, administradores e educadores sobre como planejar e implementar políticas coordenadas de saúde escolar e programas educacionais que podem promover comportamentos saudáveis entre os jovens libaneses. Os dados para o estudo foram obtidos a partir de extensas revisões de literatura e questionários dos princípios da escola e, além disso, entrevistas foram adicionadas os resultados dos dados. A pesquisa foi realizada na primavera de 2013.

Palavras-chave: Saúde, Programa de Saúde, Serviços de Saúde, Líbano, Reforma Sanitária Nacional, Educação para a Saúde Escolar.

\section{ABSTRACT}

Schools play a vital role in establishing healthy behavior patterns among young people which carry these patterns into adulthood. This article explores and collects information about school health programs and health practices in Lebanese schools. The investigation goal is to provide baseline information to school policy makers, administrators, and educators as they plan and implement coordinated school health policies and educational programs that can promote healthy behaviors among the Lebanese youth. Data for the study was obtained from extensive literature reviews and questionnaire surveys of school principles; in addition, interviews were added to the data results. The survey was conducted in the spring of year 2013.

Keywords: Health Care, Health Program, Health Service, National Health Care Reform, School Health Education.

\section{INTRODUCTION}

Students' emotional and physical health has been a key factor in the ongoing debate about schools reform. Many researchers affirm that student health is a strong predictor of academic performance. Researches confirmed that healthy, happy, active and well-nourished youth are more likely to attend school, be engaged and ready to learn. Moreover studies consistently document that poor emotionally and physically healthy, chronic medical conditions and stress-induced inability to concentrate translate into lack of achievement for students, Clayton S, Lee C, Buckelow S, Brindis C. (2002);
Hanson, T.L., Austin, G.A. \& Lee-Bayha, J. (2003/4); DeBate, R.D., Thompson, S.H., (2005); Crews, D.J., Lochbaum, M.R., Landers D.M., (2004); Strong, W.B., Malina, R.M., Blimkie, C.J., Daniels, S.R., Dishman, R.K., Gutin, B., Hergenroeder, A.C., Must, A., Nixon, P.A., Pivarnik, J.M., et al. J.Pediatr, (2005).

This article explores and collects information about school health educational programs and practices in Lebanon. This document investigates issues in the Lebanese school health programs and practices. Data for the study was obtained from questionnaire surveys of schools principle; in addition 
interviews were added to the data results.

\section{LITERATURES REVIEW}

\subsection{School health programs}

The school health education helps to empower individual, allowing students to make sensible health decisions. Health education is "the process of assisting individuals... to make informed decisions about matters affecting their personal health and the health of others" (National Task Force on the Preparation and Practice of Health Educators, 1985). Today schools' health educations are considered to be a comprehensive health curriculum; it is a joint effort of community, schools, and patient care practice. "Health education covers the continuum from disease prevention and promotion of optimal health to the detection of illness to treatment, rehabilitation, and long-term care", (Glanz, Karen, G., Rimer, B., and Marcus, F., 2002).

School health programs must incorporate the joint efforts of the educational system resources, the health system resources, and the social service resources in order to provide a full programs and services to promote healthy behaviors among young people, while enhancing their academic performance.

Fisher, and others, illustrate that school health programs account for the following eight components: "1) health services; 2) health education; 3) efforts to ensure healthy physical and social environments; 4) nutrition services; 5) physical education and other physical activities; 6 ) counseling, psychological, and social services; 7) health programs for faculty and staff; and 8) collaborative efforts of schools, families, and communities to improve the health of students, faculty, and staff", (Fisher, C., Hunt, P., Kann, L., Kolbe, L., Patterson, P., and Wechsler, H.,2013) .

\subsection{The importance of School health programs}

Give young people the knowledge they can use throughout their lives to keep themselves and others alive and healthy, productive, and content is very important. School health programs can enhance young generation knowledge and attitudes about health. It also can help them to build up communication, critical thinking, decision making, and self-management skills. School health programs also can help young people to think about how to live their lives; and build up ethical character such as such as caring, honesty, fairness, responsibility, and respect for self and others, (Lickona, T., 1991).

The Lebanese educational institutions not only generate the human resources needed for the country financial system; it also generates leadership that influences the dynamic of the social life in the country. According to latest statistics issued, the percentage of the population of children and young people of age 5-24 is enrolled in educational institutions in Lebanon is $40.1 \%$ of the total population of the country, (Table 1), (NHHEUS, 1999). Health sector cannot afford to ignore this large group of students and teachers in Lebanon. There is a need to reach out this important population group, the future builders of Lebanon. School Health Programmes will yield following benefits to the country:

- Improve the Children and young people's health conditions

- Promote healthy lifestyles and prevent disease risk and improve the quality of life in the Lebanese society at large.

- improve of the quality of education, learning outcomes and economic Growth

- Lower dropout rates and improve graduation rates

There is a critical need to initiate an inclusive School Health Programme under the support and collaboration of Ministries of Health, Environment and Education, and other donors and professional organizations.

\subsubsection{Educational Outcomes}

Lowry, and others, showed that young generations who are unhealthy are more likely to learn less than those who are healthy. On the other hand, persons who attain more learning are healthier and carry out less health risk behaviors, furthermore their offspring are also healthier and carry out fewer heath risk behaviors, (Lowry, R., Kann, L., Collins, J., and Kolbe, L., 1996). The Council of Chief State School Officers and Association of State and Territorial Health Officials, suggesting that, "Healthy kids make better students, and better students make healthy communities, (Council of Chief State School Officers and Association of State and Territorial Health Officials, 2000).

\subsubsection{Social Outcomes}

Schools are the central institutes that 
build up younger generation. Schools affect not only the academic maturity of students, but their mental, emotional, and social development as well, (National Research Council and Institute of Medicine and Committee on Community-Level Programs for Youth, 2002). Schools in Lebanon should build systems that address persistent barriers to student learning and psychological, emotional, and social development.

\subsection{Lebanon- Population}

Lebanon is a small Eastern Mediterranean country with a geographical area of $10452 \mathrm{sq} / \mathrm{km}$, and a population around $4,055,000$ million, including 500,000 refugees from different nationalities, most being Palestinians (UNRWA, 2001). The main languages used in the country are Arabic, English, and French. Ethnic background is an important factor in Lebanon. The country encompasses a great mix of cultural, religious, and ethnic groups, with a diversity of 18 religions.

Lebanon is a middle income country. The Lebanese civil war from 1975 to 1990 had a damaging effect on the economy of the country. Huge funds in restructuring the Lebanese infrastructure started in the early 90's after the end of the civil war. In consequence, there was an increasing financial deficit and public debt resulting in slowing of the growth on a national scale. Since 1999, and increasing in poverty with the rapidly increasing public debt and minimal growth effect the country severely, (NHHEUS, 1999). The population of the young between the ages of 5 and 24 is $40.1 \%$ of the total population of the country, (Table 1), (NHHEUS, 1999).

\begin{tabular}{|c|c|}
\hline Table 1 - Age Structure of the Population \\
\hline AGE & $\%$ \\
\hline $0-4$ & 8.0 \\
\hline $5-14$ & 20.0 \\
\hline $14-24$ & 20.1 \\
\hline $24-44$ & 29.4 \\
\hline $45-64$ & 15.1 \\
\hline$>65$ & 7.2 \\
\hline \multicolumn{2}{|c|}{ NHHEUS - 1999 } \\
\hline
\end{tabular}

\section{RESEARCH STUDY}

\subsection{Research Mythology}

This study investigates the school health programs and practices at Lebanese school. The investigation examines school health issues and gaps. This effort led to an understanding that can guide governments, professionals and educators to evaluate, modify, and develop school health programs in the Lebanese schools. The research results were based on the findings of literature search and on the data gathered from the questionnaire surveys and the interviews. The surveys instrument of the study was a paper survey that was used to gather data from 50 principles from 50 different schools ranging from middle to secondary schools selected from various areas in Lebanon. Each school principles completed a 10 minute questionnaire surveys; in addition interviews were added to the data results. The survey was conducted in the spring of 2013. The questionnaire surveys and the interviews were administered in Arabic language.

The schools chosen for this study were an array of ethnicities and socio-economic levels. The principles from all the different schools were treated as a single group; therefore no distinction was made among the schools. This study was conducted in a manner that protected the confidentiality of the participants. The instrument used in this study was a questionnaire administered in paper and pencil form. Survey items were developed based on an extensive literature review as well as querying participants using an exploratory questionnaire. The study gathered quantitative data to answer the research questions.

\subsection{Research Questions}

The objective of this research was to determine issues and the gaps in the Lebanese school health programs and practices. The results can strengthen our understanding and guide governments, professionals and educators to evaluate, modify, and develop school health programs in the Lebanese schools. In this research study, the following research questions were addressed. The gguiding research question:

Q1. Do Lebanese schools have school health programs?

Q2. What are the some of the weaknesses of the school's health programs?

Q3. What are the actions need to be taken in order to plan, implement, and evaluate fully functioning coordinated school health programs in Lebanese school? 


\subsection{Instrument}

The instrument used in this study was a questionnaire administered in paper and pencil form. Survey items were developed based on an extensive literature review as well as querying participants using an exploratory questionnaire. The instrument used in this study was administered in Arabic language and translated to English to serve up this research. The instrument addressed the factors, Issues, and gaps in school health programs in the Lebanese schools. The questionnaire had a 3-point Likert-type scale from disagree 1 to agree 3 was adopted for evaluation. The survey was 1 page in length and took approximately 10 minutes to finish. In order to validate the content of the survey, three expert professors were asked to evaluate the survey questionnaire. The data collected was entered into the computer and analyzed.

\section{DATA COLLECTION AND ANALYSIS}

Survey implementation and collection: During April 2013, I visited the school's principles who agreed to participate. The school's principles were given the opportunity to be involved in the study; the school's principles who decided to participate signed a paper acknowledging that this study was voluntary and that it was understood that all information would remain confidential. Each school principle was given the survey to be completed. By mid April, I collected 50 surveys questionnaires from 50 different schools. The data collected from the survey was entered in the SPSS software, for further analysis. A short fifteen mints interviews' was carry out with each school principle to further discuses issues about school health program.

\section{DATA RESULTS}

In gathering information regarding school health programs and services currently available in Lebanon, we focused specifically on the following areas:

1. What school health programs services were available at the time of the study?

2. What are the Health Risk Behaviors among Lebanese Students?

3. Who deliver the school health programs

4. Social Health Provider in Schools

5. What are the some of the weaknesses of the school's health programs?
6. Where do Schools Get funds for Health Insurance?

7. What are the some of the weaknesses of the school's Health Education in Lebanon

8. What are the actions need to be taken in order to plan, implement, and evaluate fully functioning school health programs?

The results of the survey were evaluated and analyzed.

\subsection{What school health programs services were available at the time of the study? Student health records and Medical Screening}

Student health records maintained by school employees are considered to be part of the education record. The results of the survey showed that all the school surveyed $100 \%$ reported that the schools maintain the student's health record of their students.

Many Children and young people can be saved from losing interest in their studies and dropping out when their learning struggles or illness are detected through health screening and treated at young age. The group effort between health and education sectors is essential element of school health program. The Lebanon Ministry of Education require all the school to conduct students' annual medical screening in order to protect, preserve and promote the health of students. The students' annual medical screening is obligatory by the Lebanon Ministry of Education.

All the school surveyed $100 \%$ reported that the school health program conducting a general health exam for all the students every year. The Lebanon Ministry of Education assigns the doctors who can conduct the students screening. The purpose of the yearly health examination is to evaluate health status, screen for risk factors and disease. Schools do not receive any funds from the government toward the students' annual medical screening. The medical screening cost the school \$2 per a student. All the school surveyed $100 \%$ reported that the annual medical screening is funded $100 \%$ by the Parents contribution Fund. 

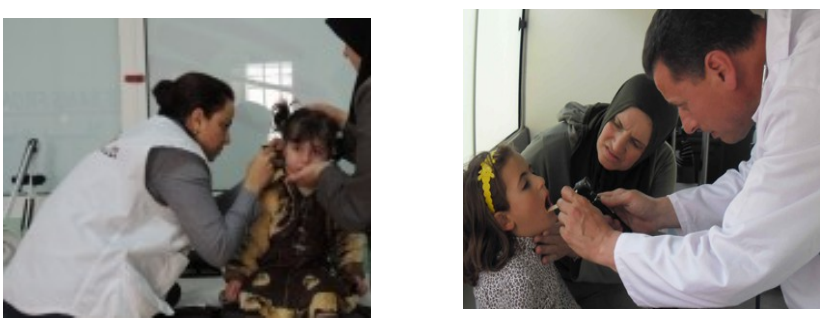

Children are being examined by doctors and health advisor to detect any sickness or health deficiency among children enables school or parents to take corrective measures

\subsection{What are the Health Risk Behaviors among Lebanese Students?}

The World Health Organization, in collaboration with the Ministry of Health and the Ministry of Education, conducted the Global School-based Student Health Survey (GSHS) in Lebanon in years 2005 and 2011, in order to evaluate the health risk behaviors and protective factors of children in grades 7,8 , and 9 . The results of the survey indicated several areas of concern:

\subsubsection{Alcohol Use}

In 2005, GSHS revealed that $20 \%$ of the students had at least one drink containing alcohol in the month preceding the survey, and $13.6 \%$ of the students got drunk one or more times during their life. In 2011, the percentage of students whom have had at least one drink containing alcohol in the month preceding the survey increased to $28.5 \%$, and the percentage of students whom got drunk one or more times during their life is $21.1 \%$, (Figure 1), (GSHS, 2005/11).

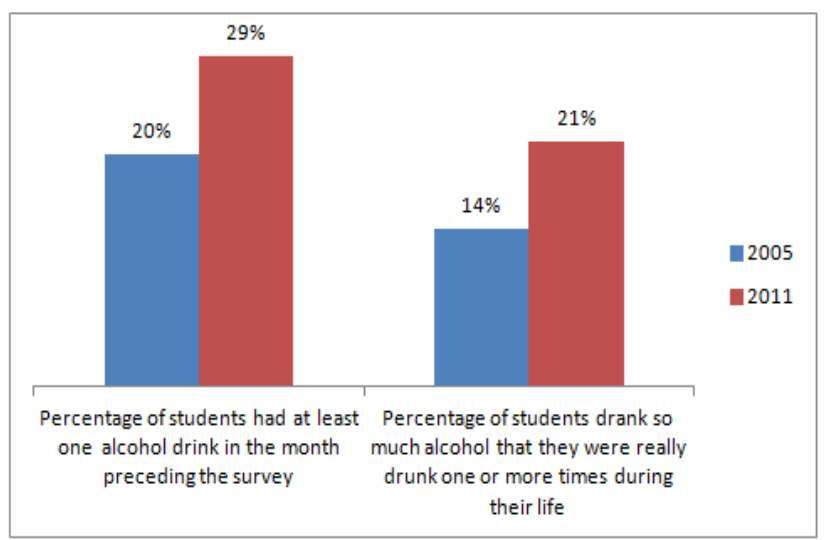

Figure 1 - Alcohol Use among grades 7, 8, and 9 students

\subsubsection{Dietary Behaviors}

In 2005, GSHS revealed that the percentage of overweight students is $23.3 \%$, and $5 \%$ were obese. In 2011, the percentage of overweight students was $24.1 \%$ and $6.7 \%$ were obese, (Figure 2), (GSHS, 2005/11).

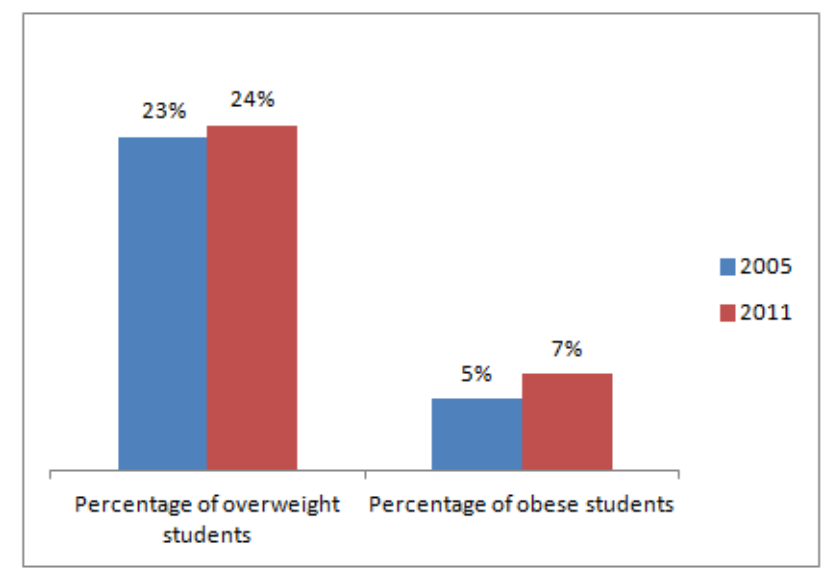

Figure 2 - Dietary Behaviors among among grades 7, 8, and 9 students

\subsubsection{Hygiene}

In 2011, GSHS revealed that the percentage of students who usually cleaned or brushed their teeth less than one time per day during the past 30 days was $9.8 \%$ and $2.4 \%$ of students never or rarely washed their hands after using the toilet or latrine during the past 30 days, (Figure 3), (GSHS, 2011).

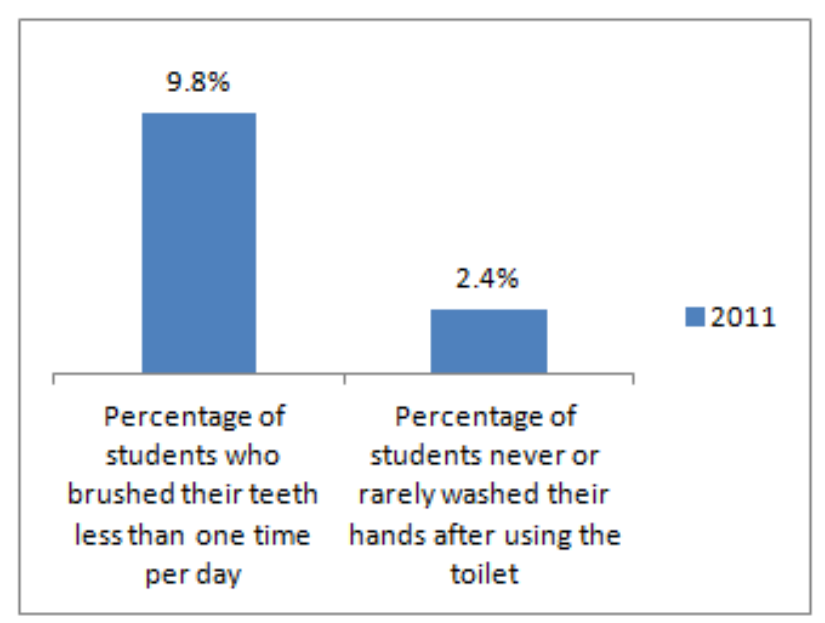

Figure 3 - Hygiene: Behaviors among among grades 7, 8 , and 9 students

\subsubsection{Mental Health}

GSHS revealed that $15 \%$ of the students seriously considered committing suicide during 
the past 12 months and $3 \%$ of the students had no close friends, (Figure 4), (GSHS, 2011).

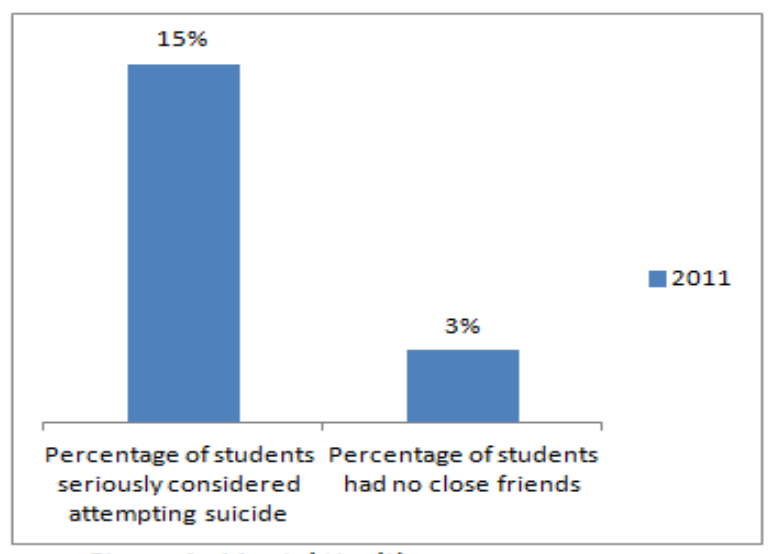

Figure 4 - Mental Health among among grades 7,8 , and 9 students

\subsubsection{Physical Activity}

Only $34.6 \%$ of the students were physically active for a total of at least 60 minutes per day on five or more days during the week preceding the survey and $33.1 \%$ of the students who went to physical education (PE) class on three or more days each week during the school year and $48.8 \%$ of the students spent three or more hours per day doing sitting activities, (Figure 5), (GSHS, 2011).

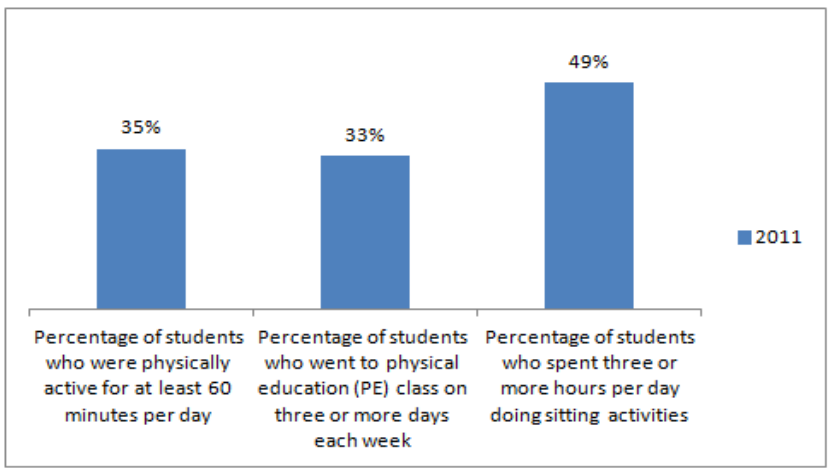

Figure 5 - Physical Activity among among grades 7, 8, and 9 students

\subsubsection{Protective Factors}

$17.5 \%$ of the students missed classes or school without permission for one or more times during the preceding 30 days before the survey, $47.8 \%$ of the parents or guardians of the students understood their children's problems and worries most of the time or always during the 30 days preceding the survey, and $53.5 \%$ of the students' parents or guardians really knew what their children were doing with their free time most of the time or always during the 30 days preceding the survey, (Figure 6), (GSHS, 2011).

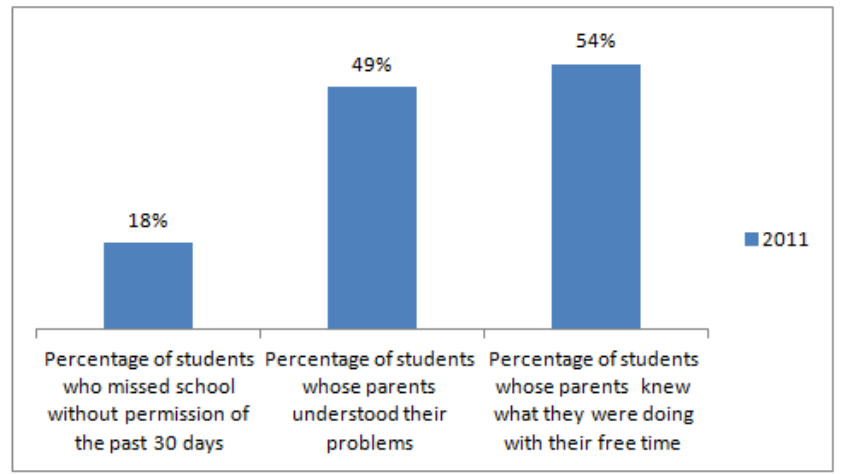

Figure 6 - Protective Factors among grades 7, 8, and 9 students

\subsubsection{Violence and Unintentional Injury}

$48.5 \%$ of the students got involved in a physical fight one or more times during the past 12 months before the survey, $39 \%$ of the students were seriously injured one or more times during the past 12 months, and $25.1 \%$ of the students were bullied on one or more days during the past 30 days before the survey was taken, (Figure 7), (GSHS, 2011).

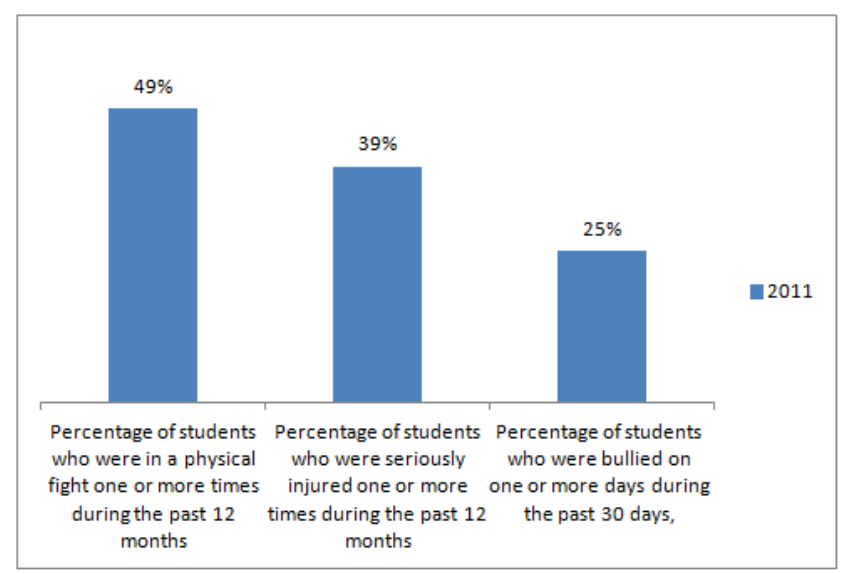

Figure 7 - Violence and Unintentional Injury Factors among grades 7, 8, and 9

\subsection{WHO DELIVER THE SCHOOL HEALTH PROGRAMS?}

Lebanese schools do not have highly educated health professionals. All the school we surveyed, $100 \%$, did not have doctor, nurse, or a social worker. A doctor visits the school once a year to conduct the students' medical screening. With increasing demand for the school health care services and a high cost to access a medical care, a health advisor used instead of professionals' health care providers. The task shifting of health care functions from 
professionally trained doctors or nurses to school health advisors are considered to be a means to make more efficient use of the school health services currently available and improving the health of the Lebanese students at low cost.

The health advisor is a school teacher who is chosen by the school to provide basic health and medical care services in the school. The School health advisors are given a very limited amount of training, supplies and support to provide essential primary health care services to students. The School health advisor work for 15 hours per week to assist in health related issues in school. The reminding if her time she works as regular teacher teaching one or more subjects within the school curriculum to students. Subjects include Geography, History, Mathematics, French, English, Arabic, Science, Social Sciences or Computer Science, (Figure 8).

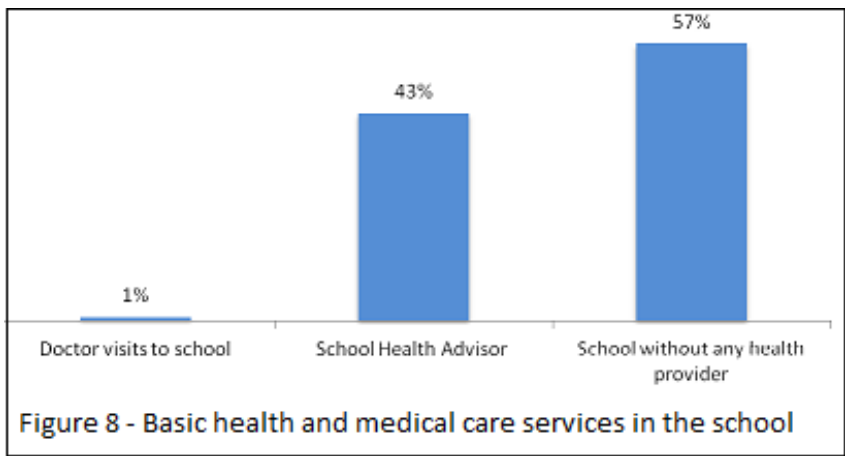

\subsubsection{Social Health Provider in Schools}

Lebanon has undergone many wars, political conflicts throughout its history. As a result a large number of Lebanese shows signs of mental health disorders - primarily mood disorder and anxiety, (WHO-AIMS, 2010). Statistic revealed that $90 \%$ of the Lebanese people with mental health disorders did not receive any treatment. In terms of support for child and adolescent health, $1 \%$ of primary and secondary schools have social health professional, and a few schools between 1-20\% have school-based activities to promote Social health and prevent mental disorders, (WHOAIMS, 2010).

\subsection{What are the hindrances of the school's health programs? The voice of school principles}

A short fifteen mints interviews' was carry out with each school principle to further discuses issues about school health program. The aim of the discussion was to listen to School principles of their observation about the hindrances of the school's health programs. The objective was to reveal some of the weaknesses of the school's health programs. The discussion also used to investigate School principles view on school's health programs. The school principles claimed that school health program has been neglected in the Lebanese public schools. Lebanese public schools face major issues with this program. The following quotes, (Table 2), highlight the school principles comments related to the deficiencies in the school health program:

Table 2 - Quotes highlight the deficiencies in the school health program

1) Lebanese public schools lack basic medicine and first aid kits.

2) School health programs lack the financial support

3) Schools lack qualified health education teachers

4) Schools lack nurses' and doctors' visits

5) Schools lack social workers. School principles complain that they have many social problems among students

6) Schools lack health room - a place where students can be treated if they get hurt - and health room supplies

7) Schools lack health education for students, parents and teachers

8) The schools' play grounds are unsafe

9) Schools do not offer healthy breakfasts to students

10) Schools lack monitoring the quality of the health adviser performances

11) Working hours of the health adviser are insufficient only 15 hours/week.

It is time for the government and the Lebanon Ministry of Education to take seriously the critical importance of ensuring that all students are healthy, engaged and ready to learn. By doing so, we will increase the chances of successful academic outcomes for all Lebanese students 


\subsection{Where do Schools Get Funds for Health Insurance?}

Having health insurance is important because coverage helps students get timely medical care they needed for them to stay healthy and focus on their studies; the uninsured students receive less medical care and less timely care. In most countries school health programs is funded by the government, but the Lebanese public schools are heavily dependent on funds obtained from other sources. The Lebanese government does not fund the public schools health Insurance. The results of the survey showed that all the school $100 \%$ reported that schools do not receive any funds toward school health insurance from the government. $90 \%$ of the school reported that they funded the school health insurance by the contributions of parents due to the inability of government to meet even basic school financial needs. $10 \%$ of the school reported that they do not have school health insurance, or any kind of insurance that covers any urgent care or an injury, (Figure 9).

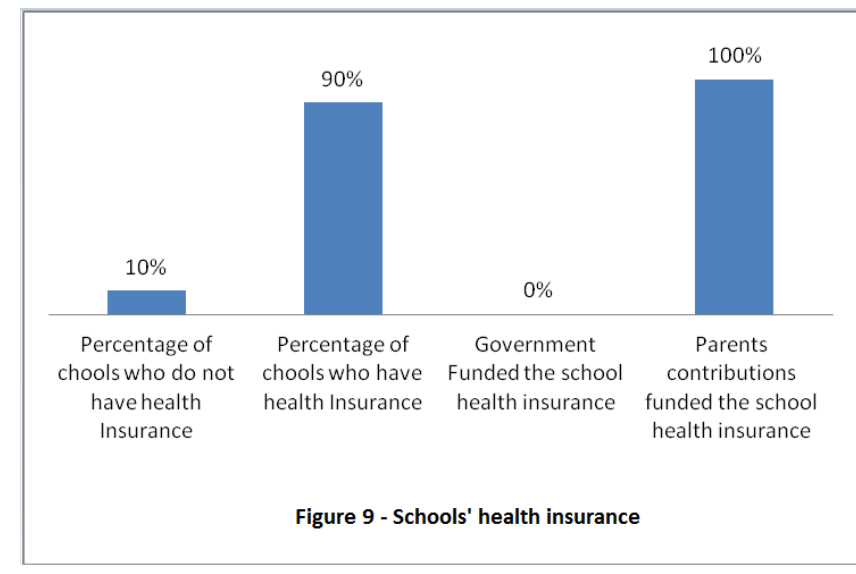

\subsection{What are the some of the weaknesses of the school's Health Education in Lebanon}

The school health education has been integrated in the Lebanese public schools education curriculum since 1987, nevertheless the performance of this curriculum has never been evaluated, (GSHS, 2005). Today school health education is seen as ineffective. The results of the survey showed that $90 \%$ of the school principles reported that school health education in the national educational curriculum is inadequate and ineffective, (Figure 11). Less than $20 \%$ of the school principles reported that their schools offers additional health educations to students through volunteers, nonprofit societies or institutions; $80 \%$ of the school principles reported that their schools do not offers any health educations to their students, (Figure 10). Global School-based Student Health Survey (GSHS) found weaknesses in the current Lebanese health curriculum, and recommended to upgraded and developed the Lebanese School Health Program in the education curriculum to include new curriculum objectives. Several objectives have been revealed in respect with the growth and development of the students in order to enable him to practice the health rules leading to his physical, psychological, and mental development, (GSHS, 2005).
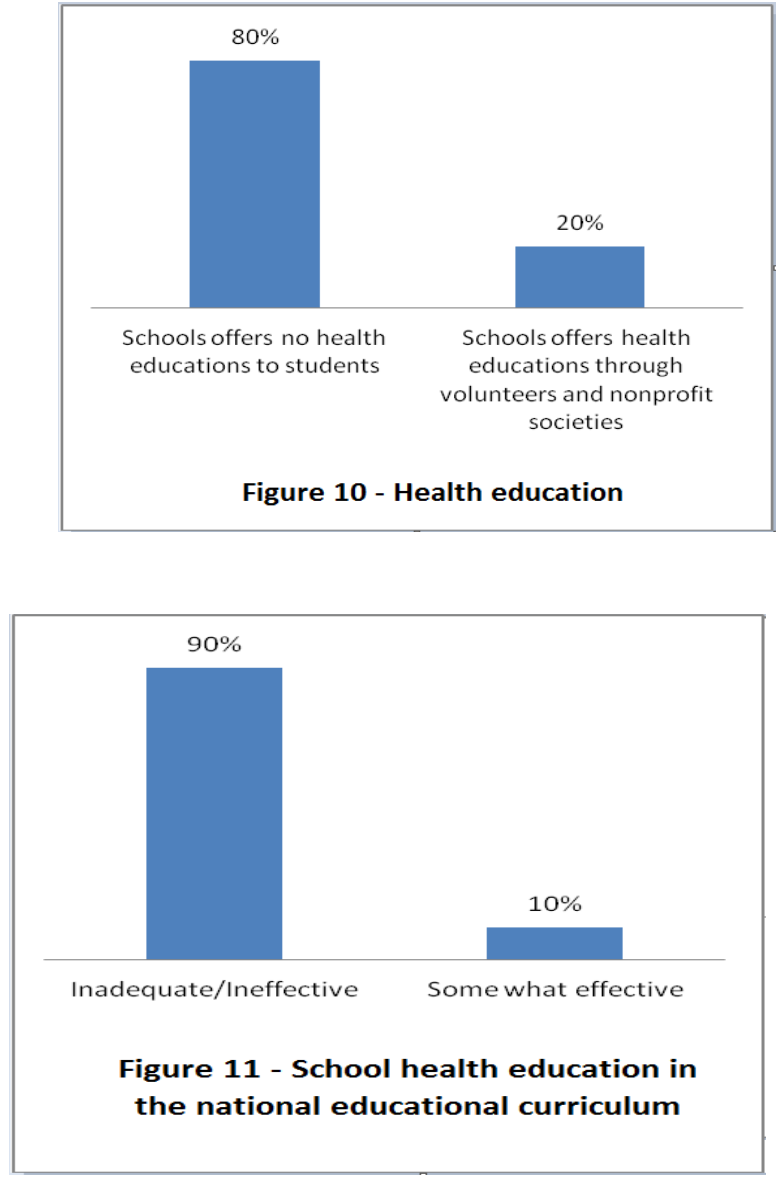

5.7. What are the actions need to be taken in order to plan, implement, and evaluate fully functioning school health programs?

In view of the fact that all children necessitate sensible guidance for a healthy future, school health programs should be established in all Lebanese schools. Improving young generation 
wellness helps them to succeed in school. It is important that government and schools policymakers should take the following steps:

- Hiring school health education teachers, school counselors, or school nurses in all Lebanese schools.

- Assessing and establishing guidelines for health and physical education, school nutrition programs, and school health services.

- Update Health education curricula and instructional practices, and assess student achievement.

- Develop and disseminate policy and resources to support Lebanese school in institute school health councils.

- Make sure that students have access to services that encourage physical activity.

- Establishing wellness programs for school staff members.

- Providing professional development for school staff responsible for delivering school health programs.

- Identify community-resource personnel and programs that complement school health policies and make these available to schools to foster community-school partnerships.

- Developed a technical-assistance plan to strengthen the efforts to improve student learning, and define professional development needs.

- Provide additional resources to improve school health programs through its publications, communications networks, and technical assistance.

- Identify appropriate media campaign materials and resources that can help local health agencies and schools promote positive health messages and programs for youth.

- Establish frameworks for allocating funds to support local school health policies and programs.

\section{DISCUSSION}

Numerous of research has provided evidence of the direct association between the health of students and their academic achievement. Healthier students have better ability to concentrate, better productivity, less discipline problems, better achievement, and more engaged in the classroom. The effect of health on school achievement should not be underestimated. Data from the survey and from the literature review should alert us. Lebanese students engage in risky health behaviors such as drinking, unhealthy eating, little or no physical activity, mental health and violence. Beyond health and academic consequences, student health problems such take an economic toll on schools. Schools have to deal with the expenses of offering additional resources and staff time to students whose academic performance or behavior suffers due to health problems. The data from the School principles interviews showed that Lebanese public schools face major issues and deficiencies in the school health program.

Encourage young people to assume healthy behaviors that minimize the possibility of chronic diseases are a constant challenge and should be the aim of school health programs. Accomplishing this objective requires cooperation and collaboration among many partners and agencies. Government and policymakers should accept the responsibility to effectively enhance school health programs. Departments of education and health should make every effort to coordinate structured programs that address the health needs of young people (e.g., Health, chronic disease, physical activity, Safety, nutrition, and tobacco control); and to discourage unhealthy behaviors in order to reduce young people's risk for chronic disease later in life

Reducing health-risk behaviors among young people is a complex effort. Government and policymakers should ensure that these structured programs can: 1) provide high-level team members to coordinate, support, and evaluate school health programs; 2) build a training and development system for health and education professionals; and 3) draw together different organizations to develop and coordinate programs that address the health needs of young people.

\section{CONCLUSION}

The poor quality of school health programs in 
Lebanon is clear. As this study has demonstrated, there is an urgent need for a comprehensive school health care reform plan. Government and policymakers should establish processes for identifying, developing, and disseminating resources for supporting coordinated school health programs and put into practice health guidelines at the Lebanese schools. Our kids would be best served by the creation of subcommittees to address gaps and barriers in school health care and health education providing adequate primary care, health education and preventative care for healthy lifestyles, which will all help control costs. The cumulative effect of unhealthy behaviors and unsafe living environments is poor health outcomes and higher costs. I'd like to conclude with an appropriate quote that says, - In the end, it's not what we don't know that will destroy us, but rather the failure to respond appropriately to what we do know.

\section{REFERENCES}

1. Clayton S, Lee C, Buckelow S, Brindis C. (2002). CA Adolescent Health Collaborative policy brief. Improving Teen Health Care Access Through Teen-Oriented Outreach. California Adolescent Health Collaborative. Available online at: http://www.californiateenhealth.org/download/teen_outreach.pdf

2. Council of Chief State School Officers and Association of State and Territorial Health Officials, (2000), Why Support a Coordinated Approach to School Health? (Washington, DC: Council of Chief State School Officers.

3. Crews DJ, Lochbaum MR, Landers DM. (2004) "Aerobic physical activity effects on psychological well-being in low-income Hispanic children."

4. DeBate RD, Thompson SH., (2005), "Girls on the Run: improvements in selfesteem, body size satisfaction and eating attitudes/behaviors." Eat. Weight.Disord. 2005 Mar;10(1):25-32.

5. Donatelle, R. (2009). Promoting Healthy Behavior Change. Health: The basics. (pp. 4). 8th edition. San Francisco, CA: Pearson Education, Inc.
6. Fisher, C., Hunt, P., Kann, L., Kolbe, L., Patterson, B., Wechsler, H.,(2013), BUILDING A HEALTHIER FUTURE THROUGH SCHOOL HEALTH PROGRAMS. Adolescent and School Health, Centers for Disease Control and Prevention, Coordinated School Health Publications \& Resources, nta, GA 30333, USA available at www.cdc.gov/healthyyouth/publications/p df/PP-Ch9.pdf

7. Glanz, Karen, G., Rimer, B., and Marcus, F., (2002), Health Behavior and Health Education: Theory, Research, and Practice. San Francisco: Jossey-Bass.

8. GSHS, (2005/2011). Lebanon 2005/2011 Global School based Student Health Survey. Available at http://www.cdc.gov/gshs/countries/eastme diter/lebanon.htm,

9. Hanson, T. L., Austin, G. A., \& LeeBayha, J. (2003). Student health risks, resilience, and academic performance: Year 1 report. San Francisco: WestEd. Available online at: www.wested.org/hks

10. Hanson, T.L, Austin, G.A. \& Lee-Bayha, J. (2004). Ensuring No Child Left Behind: How are student health \& risk resilence related to the academ ic progress of schools? San Francisco: WestEd. Available online at: www.wested.org/chks.

11. Lickona, T., (1991), Educating For Responsibility: How Our Schools Can Teach Respect and Responsibility (New York: Bantam Books.

12. Lowry, R., Kann, L., Collins, J., and Kolbe, L., (1996). "The Effect of Socioeconomic Status on Chronic Disease Risk Behaviors Among U.S. Adolescents," Journal of the American Medical Association 276, no. 10 (11 September 1996).

13. National Household Health Expenditure and Utilization Survey (1999), Ministry of Public Health. 
14. National Research Council and Institute of Medicine and Committee on CommunityLevel, (2002), Programs for Youth, Community Programs to Promote Youth Development (Washington, DC: National Academy Press.

15. National Task Force on the Preparation and Practice of Health Educators. (1985). A Framework for the Development of CompetencyBased Curricula. New York: national Task Force, Inc.
16. UNRWA, UNRWA, Annual report of the Department of Health, 2001

17. Strong WB, Malina RM, Blimkie CJ, Daniels SR, Dishman RK, Gutin B, Hergenroeder AC, Must A, Nixon PA, Pivarnik JM, et al. J.Pediatr, (2005). "Evidence based physical activity for school-age youth". J.Pediatr. 2005 Jun;146(6):732-7.

18. WHO-AIMS, (2010). A report of the assessment of the mental health system in Lebanon using the World Health Organization - Assessment Instrument for Mental Health, Ministry of Health, Beirut , Leban 